\title{
School libraries as windows to the world
}

\author{
Raghunathan. M.O \\ Senior Librarian, \\ The Westminster School, \\ Dubai, U.A.E. \\ moraghunath@gmail.com
}

\begin{abstract}
The purpose of this paper is to show the possibilities of school libraries as windows to the world of information through various activities. This paper outlines and discusses the last few years of successful professional experience on Multiple Intelligence Based Projects in the library along with Reading Challenge activities.
\end{abstract}

Keywords: Curriculum, Research, Collaborative learning, Growing, Communication, Presentation skills, Motivation, Reading habits, U.A.E., Dubai

\section{Introduction}

The 21st century is the era of knowledge explosion and so as a concomitant the library should be the place to provide the right and latest information to its users. The librarian has to carry out his role more effectively and efficiently to provide his resource and service to the users. This is not a question of the technical methods in the field of Library Science, but the library staff should be better equipped to ensure and to provide the best possible service to the regular library users.

The main and primary object of a school library is to support the school curriculum. The school library should provide a model of inquiry learning and build up knowledge with high level confidence in seeking and processing information. The school library is pivotal to develop 21st Century learners. Inquiry Learning requires students to develop a range of critical multi-literate skills to work in authentic, problem solving situations, decision making skills, and consideration of multiple intelligence or viewpoints to arrive at their own evidence based conclusions.

To ensure the 21st Century learning skills, the library should support the learning pathways where they provide positive, reflective and supportive learning environments for students who have a range of practical research experiences, and cultural backgrounds. The library has to consistently collect and give organized access to information from multiple viewpoints over various ranges of disciplines and knowledge systems, presented in a range of formats. The use of inquiry approach in the student's interaction is highly important.

The collaboration and partnership between the library staff and the teachers have a keen role in the present academic structure. School librarians are a part of professional literacy team in the school who encourage students to make meaningful learning through exposure to the knowledge of multiple texts in an interesting and supportive library environment. The learning 
outcomes and evidence from the school library perspective can be used to assist in the process of decision-making, development and continuous improvement to achieve the goals of the institution that focus on student achievement and quality of teaching and learning.

\section{Main Objectives}

To show the implementation of 21 st Century Learning Skills in the school library through;

- Reading Challenge Activity

- Project Based Learning Approach

\section{Reading Challenge}

The Reading Challenge activity is conducted in the library to encourage book borrowing habits among students. The aim is to portray how a Reading Challenge activity has given better results to our students' reading habits, as well as, it increases the circulation of library books. The significant implementation of the Reading Challenge has added another dimension and has produced better results in our students' reading performance in the Library.

A series of activities have to be planned and implemented to support the Reading Challenge activities in the library. The library stocks are updated with renowned author's books with multiple copies and arranged aesthetically. The large number of books purchased for the library, especially new series of popular fiction and 'best sellers' books, suggested by students according to their aptitude and interest. Therefore students participate in the selection of library books. The arrangements of book shelves with some innovatively designed shapes help to create a pleasant library atmosphere to encourage the students. Students have maintained their Library Notebook with the summary and review of the borrowed books. The Best Reader Awards are considered at the end of the Academic Year for the deserving students on the basis of the maximum number of borrowed books with clear evidence in the Library Notebook.

\section{Supportive Activities}

The significant implementation of the Reading Challenge activity has seen a tremendous positive impact on our students' reading habits. Students participate and enjoy getting involved in activities like Book Review presentations, Read Aloud, Writing Skill activities, Literacy quiz, Debates, Elocution, Story writing, and many more. The library staff coordinates these activities and also uses the help of the English language teachers to implement various activities.

The Main supportive activities for the Reading Challenge are;

- Poster Advertising: The Reading Challenge Award poster advertisement in the classrooms will help to increase the participation and create a competitive situation among students.

- Book Selection: The book selection is very important in a library. The students' participation will be done in the book selection through their suggestions. It helps the librarian to understand the exact demand of the books and lead to purchase multiple copies of the same. This makes the Students feel they are part of the library. 
- Book Reviews: Students have to maintain a Library Notebook and update them with the summary and reviews of the books read. Students can also present their review and reports about the books in the library during their regular library period. The drawing and illustration work done by students as part of the book review should be displayed on the library bulletin boards.

- Read Aloud: Students are encouraged to read aloud a particular paragraph within a limited time. Certain criteria have to be used to evaluate the reading performance of the students. Criteria: Intonation, Pronunciation, Diction, etc.

- Writing Skill Activities: Writing skill activities like Read between the lines, Argumentative writing, etc. can be conducted in the library. A short story is displayed in the library using TV monitor; and students have to summarize the story after reading and try to explain the hidden meaning between the storylines.

- Literacy Quiz: Students are asked to prepare questionnaires from the library books they have read and present the same in front of their classmates during the regular period.

- Debates: Debates are conducted in the regular library period on particular topic from one of a famous book/book series in the library. Students have to write their arguments (individually or group wise) and summarize the story.

- Elocution: The elocution contest is held in the library on the basis of a famous author/famous book or a famous quote. The evaluation process is done with the help of English language teachers.

- Awards: The Awards and Certificates are given according to the reading performance of the students. The Award Ceremony is held in the library or any other suitable hall in the school at the end of the Academic Year and the Best Reader Awards are given to the winners. 
Reading Analysis: Academic Year 2013-2014 (Key Stage wise)
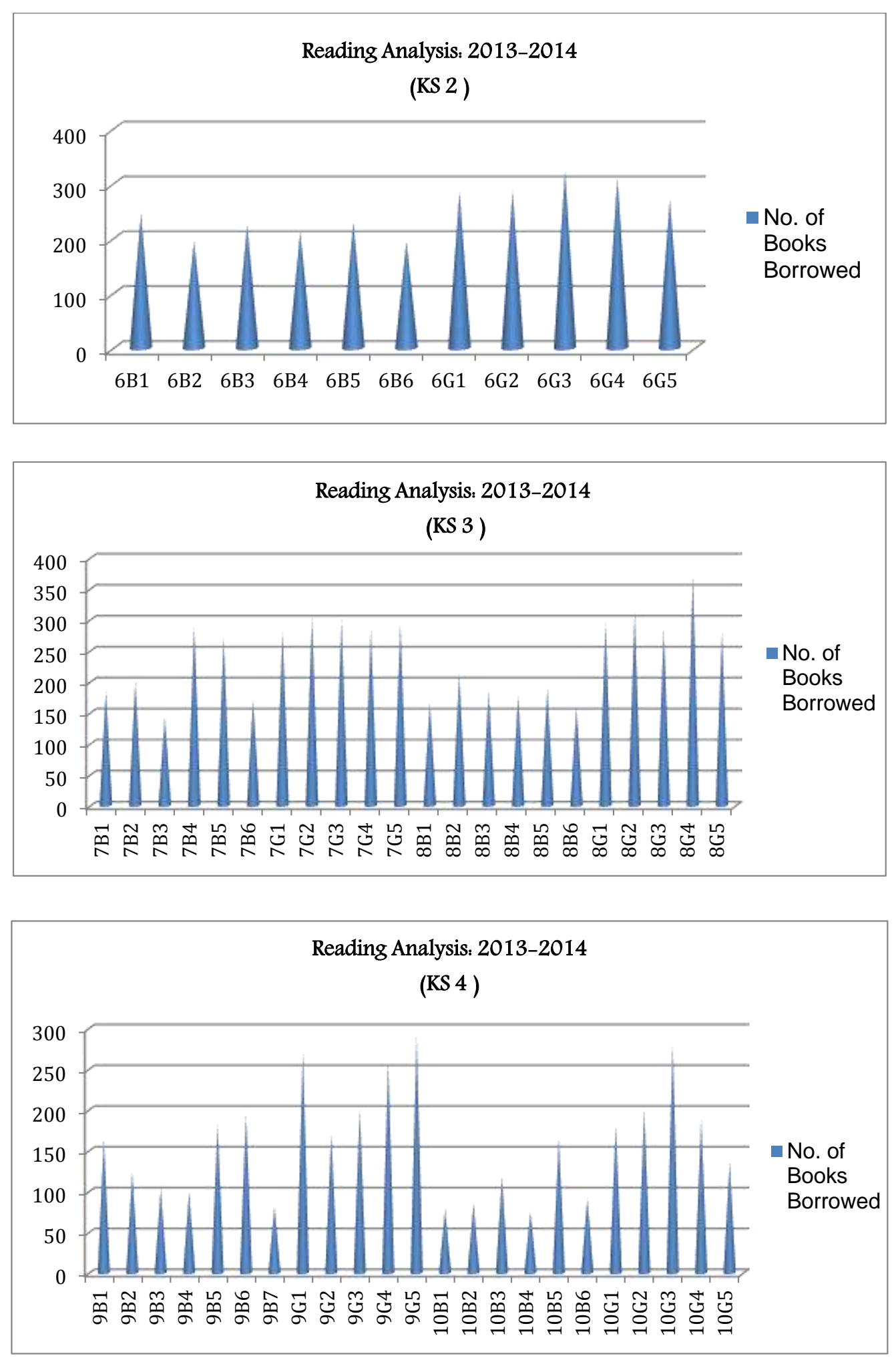


\section{Reading Challenge: Book Circulation Growth Analysis}

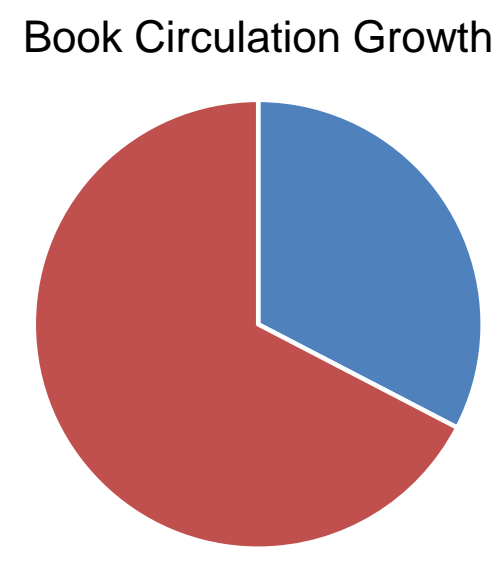

- 2011-12

\section{Project Based Learning}

Projects are complex tasks, based on challenging questions or problems that involve students in designing problem solving, decision making or investigating activities aligned with the curriculum. Students do research in their group and present the project in the library during their library period. The application of Cross Curriculum, Multiple Intelligence and the Collaborative Leadership has been done through the Project Based Learning Activity. The students' participation and performance in Project Based Learning in the Library are always more interesting than the Classroom curriculum activities. Students do research with their team and present the online project in the library during their library period.

Students do research with their team and present the project during their library period. It covers the $21^{\text {st }}$ Century Learning Skill processes like collaborative learning, knowledge construction, self-regulation, problem solving \& innovation skills, the use of ICT for learning \& skilled communication. The ICT section of the library supports the curriculum based research, online project preparation, blogging, etc. The applications of Cross Curriculum, Multiple Intelligence, Collaborative Leadership and Teamwork are done through the subject project.

Students do Project presentation on various subjects during their library period. The librarian should coordinate the activities with the proper collaboration of teachers, Head of Subjects, Supervisors; by extending their hours of operation during school hours. The Score Sheets for continuous evaluations are maintained by the Library staff with the help of Senior Students. The library is always engaged by students, resulting in the maximum utilization of library resources. The online projects and performance photos are uploaded regularly in the respective Class blogs and Library Blog by the Student Blog Administrator and the Librarian respectively. The implementation of Multiple Intelligence Projects has improved the academic knowledge and student engagement in the library. 
The subject topics are given according to the monthly theme of the School. The Project and Theme Based Approach are shared to give them the opportunity to research and present projects during their library hours. Students conduct research in their teams and present their projects during their library period. This initiative caters to the students' 21 st Century Learning Skills through collaboration, knowledge construction, self-regulation, problem solving \& innovation skills, the use of ICT for learning \& skilled communication. The applications of Cross Curriculum, Multiple Intelligence, Collaborative Leadership and Teamwork are also done through subject projects. The students collaborate to produce the final product or outcome through their Project presentation in the Library.

\section{Learning Activity- Main Objects}

- Any task that students do as part of the curriculum based Approach.

- It can be an exercise that students complete in one library period/ an extended project that takes place both in and outside of school.

\section{Learning Skill Process}

The main learning skill processes are given below;

- Collaboration

- Knowledge construction \& Self-regulation

- Problem solving and innovation

- Use of ICT for Learning \& Skilled communication 


\section{$21^{\text {st }}$ Century Learning Skills: Activity Plan}

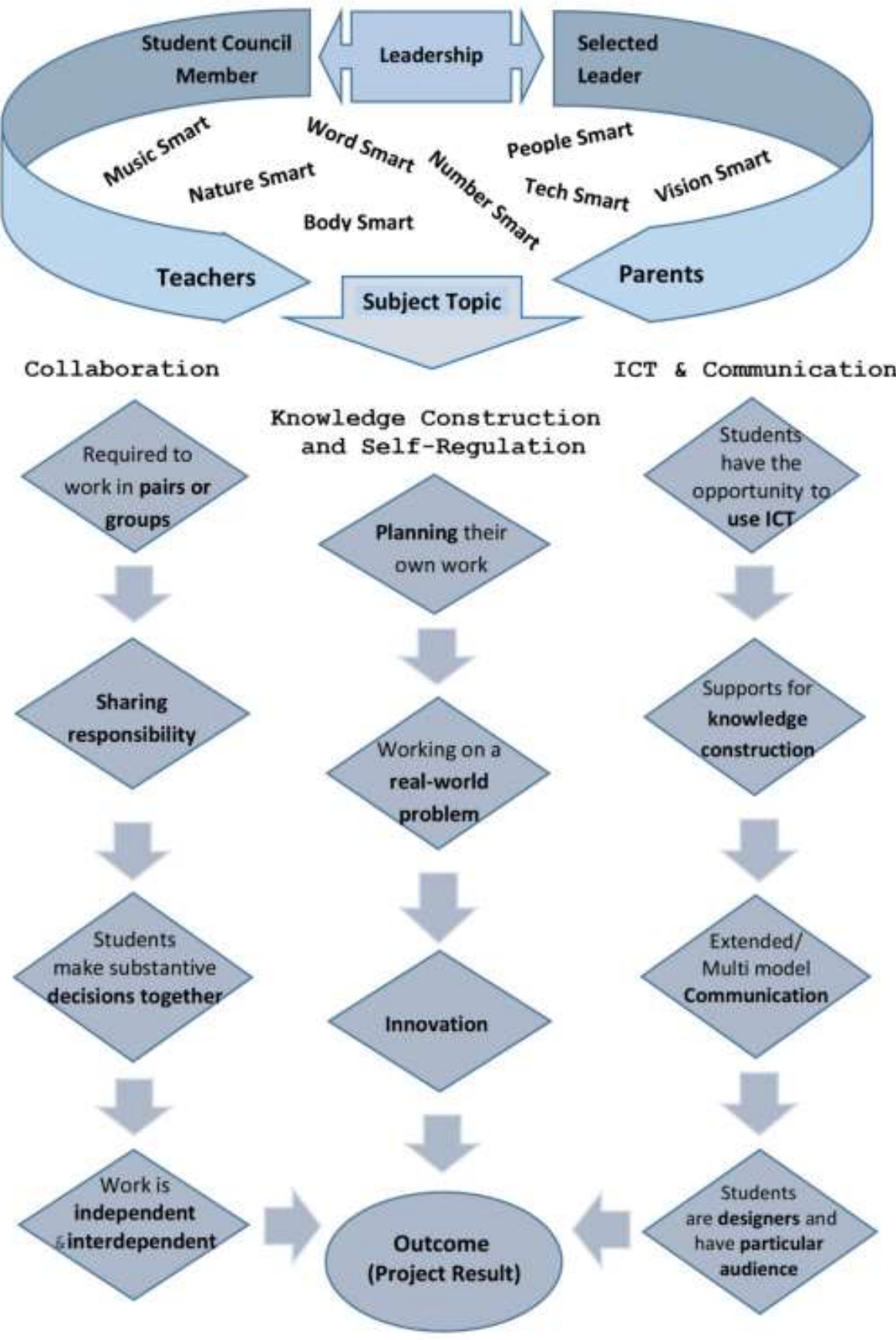




\section{Collaboration}

It is an independent and interdependent process. Divide the Roles \& Responsibilities according to the Smartness of the team members. The teams has to solve the problem, Share ideas with .each other, Get the Solution or Take a Decision or create a product, Levels of Accountability (i.e.; individual \& group accountability), etc.

Important steps in the Collaborative works are:

- Make substantive Decisions together (Get the Subject topic, Discuss the issue/topic, Fix the Object)

- Set the Plan (What to do, When to do, How to do, which tools to be used, etc.)

- Do independent Research (with the help of Reference Books, Internet, Teachers, Parents, etc.)

\section{Knowledge construction and Self-Regulation}

An interdisciplinary action requires students to generate ideas through interpretation, analysis, synthesis, or evaluation and understanding that what is new to them.

a) Students plan their own work

b) Students can complete this activity by reproducing information or by using familiar procedures without any external control.

c) Application of the constructed knowledge in a different context and share with the team (Application of Cross-Curricular Skill).

d) Students have the opportunity to revise work based on feedback.

\section{Problem solving and Innovation}

This activity examines whether students' work involves problem-solving and they use the data or situations from the real world.

- Students must develop a solution to a problem that is new to them OR

- Complete a task that they have not been instructed how to do OR

- Design a complex product that meets a set of requirements.

This task requires students do some or all of the following:

(a) Investigate the parameters of the problem to guide their approach

(b) Generate ideas and alternatives

(c) Explore several possible procedures that might be appropriate to the situation

(d) Design a coherent solution

(e) Test the solution and iterate on improvements to satisfy the requirements of the problem.

Example:

- Find the Scientific reason behind Subject topic (Scientific Skill).

\section{Use of ICT for Learning and Skilled communication}

The students are required to use ICT or can use ICT directly to complete the learning activities. Students can access information of various types such as online database, ejournals, and e- books through networked systems. Libraries can use the internet or CD ROMS to educate the students or carry out information literacy programs. Online searching through various search engines is very common in academic libraries. 
Social media networks and various blogs are some interactive internet services that are presently serving as communication forum for librarians and the students. Emails have better and simple options of communication between the librarian and the students. Library website is another good medium of communication for libraries to the students and staff. It is also used to promote the library activities and publicize it.

\section{Examples:}

- Students use the Internet to find newspaper articles about a current event from different countries, and analyses how the perspectives are similar or different (Communication with Multimedia Skills).

- Students create videos of their own interviews with local community members that will be uploaded in their project and class blog.

- The online projects and performance photos can be uploaded regularly in the class blog and library blog with the help of student bloggers and the librarian respectively.

\section{Background Research}

In the Project \& Theme based approach, students are able to present their Project on various subjects during their regular library period. The librarian coordinates and provides the instructions for the project process. The activities are held in the library with proper collaboration of Head of Subjects and Phase Leaders; by extending their hours of operation during school hours. The library is always engaged with students, resulting in the maximum utilization of library resources. The online projects and performance photos are uploaded regularly in the respective Class Blogs and Library Blog by the Student Blog Administrators and the Librarian respectively. The implementation of Multiple Intelligence Projects has improved the academic knowledge and student engagement in the library. 


\section{LEARNING RESOURCE CENTRE}

\section{PROJECT BASED LEARNING: TEAM STRUCTURE}

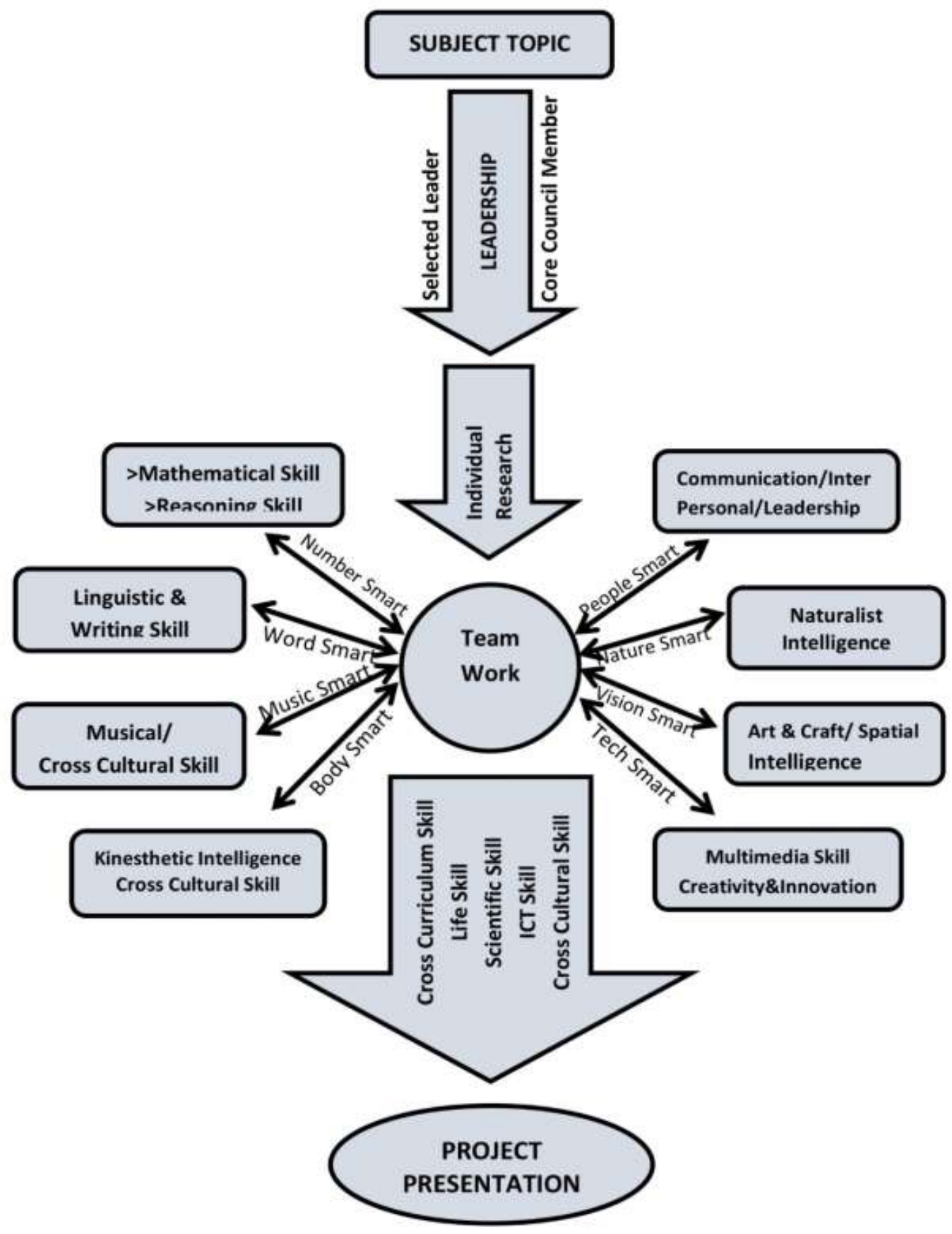


PROJECT BASED LEARNING

\section{PERFORMANCE EVALUATION SCORE SHEET}

Subject:

Learning Bay:

Team Leader:

Team Members
Topic:

Date:

\section{Criteria}

The Aim/Goals of the project

- The objective is what the team is trying to achieve. Approaches, Observation Skill etc.

- The quality of approach is a general way of thinking about conducting research (Ground work done by the pupil).

Quality of Explanation \& Clarity of Expression

- The depth in discussing the topic in detail.

- Presentation based on project must be easy to understand; the comprehensibility of clear expression

Quality of the Presentation

Level/Application of:

\section{Commitment to Leadership}

Cross Curriculum

Scientific Skills

ICT/Multimedia Skills

Creativity \& Innovation

Original Thinking

Life Skill

Cross Cultural Skills

- How the students and the team mates committed to leadership and service in the community.

Application of Multiple Intelligence

- In what ways will the students involved in the project reflect upon and learn from their team work experience.

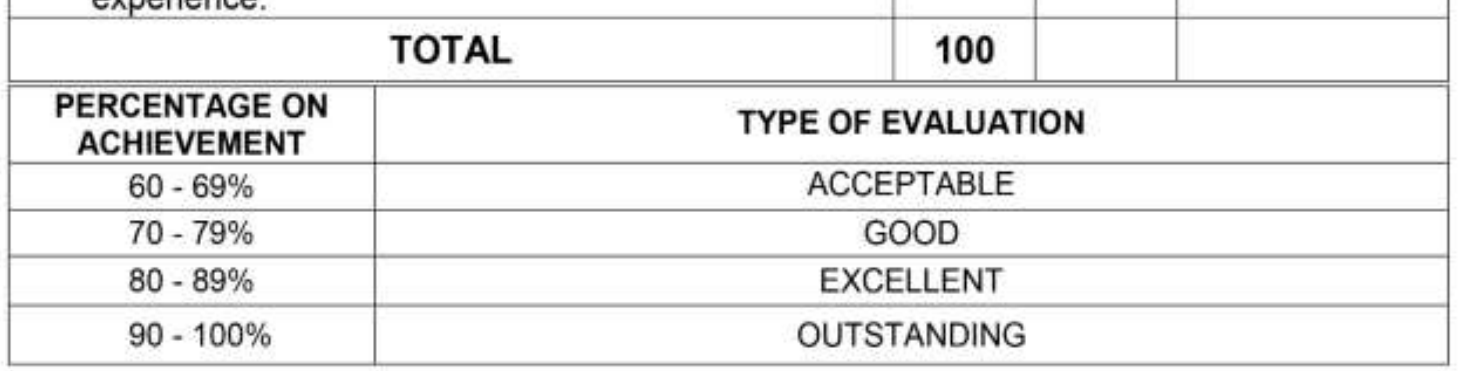

Student Leader:

Librarian: 


\section{Role of the Library in the project Based Learning Approach}

The Library can contribute to improve the student achievement by providing;

- Guidance \& Orientation: As a Project Based Learning Coordinator, the librarian has to create the plan and performance criteria for the Project Based Learning Approach and he/she has to provide the proper guidance to the students. A guideline aims to streamline particular processes according to a set routine or sound practice.

- Resource Materials: The library has to provide various resources to do the student's research in the form of Reference books, Computers, Internet facilities, etc. Students can refer to the library resources and can get the help from the Subject teachers during the research period of their projects.

- The Presentation Platform \& TV monitor: One small size stage and a TV monitor is permanently fixed in the library for the comfortable presentation of the students' projects during the library hours.

- Announcing Subject Topics: As per the suggestions from the respective Head of Subjects, the librarian should announce the Project Based learning topics in the library. All the Project topics should be displayed on the library bulletin board.

- Evaluation: The Project presentation evaluation and Subject wise evaluation is done with the help of the Senior Students/ Student Leaders and subject teachers respectively. The Score Sheets for the students' Project Presentation performance is maintained in the library.

All the above roles should be collaborated with teachers, Head of Subjects and Phase Leaders/Supervisors; and by extending their hours of operation during the school day.

\section{Application of various Learning Skills}

Students do research with their team and present the project in the library during their library period. The applications of Cross Curriculum, Multiple Intelligence, Collaborative Leadership and Teamwork have been done through subject projects.

\section{Multiple Intelligences}

The curriculum knowledge is improved by addressing Multiple Intelligences to students. People have all of the intelligence, but each person has a unique combination. Each student has a different intellectual composition. We can improve each of the intellects, through the application of Multiple Intelligence based activities among students. Many types of intelligence reflect different ways of interest to the world. Student prefers to learn through in multiple intelligent groups and share their ideas with each other. Students become more active, involved learners in the application of Multiple Intelligence approach.

The application of Multiple Intelligence provides opportunities for authentic learning based on the students' interests, needs and talents. Students become more active, involved learners and may come to regard intellectual ability more broadly. Drawing a picture, implementing mathematical application, writing poems, composing music or listening to music, writing plays and acting the same, watching various performances like activities can be a vital door to learning. Experiences show that many students who perform poorly on traditional methods 
and tests are turned on to learning when the classroom experiences incorporate artistic, athletic, and musical activities.

The learning style of Multiple Intelligence based Project Approach shows various smartness. They are;

- Linguistic intelligence (Word Smart)

- Logical-Mathematical intelligence (Number Smart)

- Kinesthetic intelligence (Body Smart)

- Naturalist intelligence (Nature Smart)

- Spatial intelligence (Picture Smart)

- Musical intelligence (Music Smart)

- Intrapersonal intelligence (Self Smart)

- Interpersonal intelligence (People Smart)

- Technical intelligence (Tech Smart)

Each person has a different intellectual composition. We can improve education by addressing the Multiple Intelligence of our students. Experiences show that many students who perform poorly and less interest in traditional method of study and tests are turned on to learning when the learning experiences incorporate artistic or musical activities. Project activities involving apprenticeship learning bring members of the student team into the learning process. Parent and community involvement in the school will increase, because students always get help and demonstrate their project work to the parents before the audience. Students are able to demonstrate and share their strengths. This can in turn lead to increased self-esteem. A few of the skills that make it possible for a person to solve problems in real life that students accumulate are positive educational experiences and the capability for creating solutions to problems in the real life. The potential for finding or creating solutions for problems involves gathering new knowledge. Multiple Intelligences provide opportunities for authentic learning based on students' needs, interests and talents.

\section{Teamwork}

For small groups to function effectively in a course context, students must attend to both the situation within their group and the process by which they accomplish their tasks. A team should consist of all the different smart groups and the responsibilities must be shared according to their smartness. The structure of the team and the individual role \& responsibilities of each team members has to be mentioned in the project. Creating a healthy atmosphere and effective process improves communication skills. Students gain many of the skills, if they work together in a particular manner to complete their task. No Multiple Intelligence can be achieved, if a task does not have teamwork.

To function successfully in a small group, students need to be able to communicate clearly on intellectual and emotional levels.

Effective communication will;

- express their feelings in an open way,

- explain their own ideas,

- listen carefully to others, ask questions to clarify others' ideas and emotions,

- initiate conversations about task process, 
- reflect on the activities and interactions of the group and encourage other group members to do so as well, etc.

To work together successfully, group members must demonstrate a sense of cohesion. Regular open communication, in which group members share their thoughts, ideas, and feelings this is a must for successful group work. Unspoken assumptions and issues can be very destructive to productive group functioning. When students are willing to communicate openly with one another, a healthy climate will emerge and an effective process can be followed.

Group members are willing to get to know one another, particularly those with different interests and backgrounds. They are open to new ideas, diverse viewpoints, and the variety of individuals present within the group. The team members listen to others and disclose their ideas. They know how to balance the need for cohesion within a group with the need for individual expression. Group members trust one another enough to share their own ideas and feelings. Team members demonstrate support for one another as they accomplish their goals. Student members in a team communicate their opinions in a respective way and focus on the learning object.

As a Project Based Learning Coordinator, the librarian can use several strategies to encourage students to develop a healthy atmosphere within their small groups. The librarian has to assign students into diverse groups so that they encounter others with different smartness and interests. An effective teamwork process will emerge as students exhibit various skills like, Individual responsibility and accountabilities, Problem solving, Management and organization, Knowledge of individual roles in a group, Constructive Feedback about group ideas, etc. For the application of Multiple Intelligence, the teamwork approach is necessary.

\section{Leadership}

Leaders help themselves and others to do the right things. The People Smart student will be normally a team leader in the Project Based Learning approach. Leaders motivate and inspire the team members to engage with the project. Find and understand the interest and smartness of the team members and divide the project responsibilities according to the same.

One of the Class Core Council members or any selected leader from the same classroom must lead the team. The leader has to divide the individual responsibilities among the team according to the smartness of the team members. Especially the Cross-curricular activities should be done by team individuals on the basis of their smartness.

\section{Cross-curriculum}

The main object of Cross-curricular learning is to make thinking skills more explicit in teaching and learning. The Cross-Curricular activities have to be planned in accordance to the Smartness of the team members. It has to explore if students could adapt their use of thinking skills to different learning contexts and break down subject barriers. This process has to assess how effectively students complete this work collaboratively. This activity suggests that the greatest benefits were experienced when there was dedicated time to 'thinking skills', when it is given discrete curriculum time, and undertaken in an explicitly collaborative setting. This enquiry has opened many possibilities to develop students' 
thinking skills practice. The approach has encouraged students to see how thinking skills, like sorting and classifying, can enable them to approach a topic from a different angle. It also seems to help them to see the transferability of such skills across their learning in a range of subjects. This could lead to a greater awareness of themselves as learners, and how they learn. Ultimately, the students are engaged and totally focused on the tasks at hand on that particular day.

Students have to connect their project subjects with other subject areas and apply various skills (including music, picture, illustration, numbers, etc.) from the same that leads to deeper understanding. Cross-curricular work offers a creative way to develop children's knowledge, skills and understanding while motivating them to learn through stimulating, interconnected topics. A study which crosses subject boundaries allows for investigations that engage children's imagination. It also gives teachers and librarians opportunities to encourage active enquiry, taking the initiative, and discussion and debate by children. In all cross-curricular process, the experience provides an ideal context for extending children's literacy, in speaking and listening, reading and writing. Students will use and apply the subject knowledge in the course of a cross-curricular topic and tackling substantive concepts, knowledge or skills in all the subjects included in the topic.

In the Cross-curricular activity, students make real progress in each subject. Cross-curricular learning method increase students' motivation for learning and their level of engagement. In contrast to learning skills in isolation, when students participate in interdisciplinary experiences they see the value of what they are learning and become more actively engaged. The Cross-Curricular learning provides the conditions under which effective learning occurs. Students learn more when they use the language arts skills to explore what they are learning, write about what they are learning, and interact with their classmates, teachers, and members of the community. Students and teachers alike enjoy reading and learning about curriculum topics and ideas that are interesting and challenging. These acquire, communicate, and investigate worthwhile knowledge in depth. The Cross-curricular skills Integrate and enrich the language processes of reading, writing, listening, speaking, and thinking. One of the most important advantages of cross- curricular thematic instruction is that it is both flexible and adaptable. Because a variety of reading resources are utilized, all students have the opportunity to read materials that are of interest to them and at the appropriate difficulty level. For students, it allows for a variety of approaches to instruction that meets their needs.

\section{Examples:}

- Apply the constructed knowledge on various communities in the world (Cross Cultural Skill)

- Show graphical explanation of collected data (Mathematical Skill)

\section{Life Skills}

The goal of the Project Based Learning is to assess the progress in the life skill development of the participating children. Life skills inventory includes statements for six constructs of life skills including teamwork, self-understanding, leadership, decision making skills, communication skills, and volunteerism. 
Example:

- Get the abilities regarded as essential to effective and efficient functioning in the modern society.

\section{PBL: Sample Graphical Analysis}

Subject: Environmental Science

(Activity Period: October-November 2013)

\begin{tabular}{|c|c|}
\hline Year Level & Project Topics \\
\hline 6 & Conservation of Environment \\
\hline 7 & Climate Change and Global Warming \\
\hline 8 & Loss of Biodiversity and Extinctions \\
\hline 9 & Recycling electronic waste \\
\hline 10 & Strategies for sustainable schools (Eco-friendly schools) \\
\hline
\end{tabular}

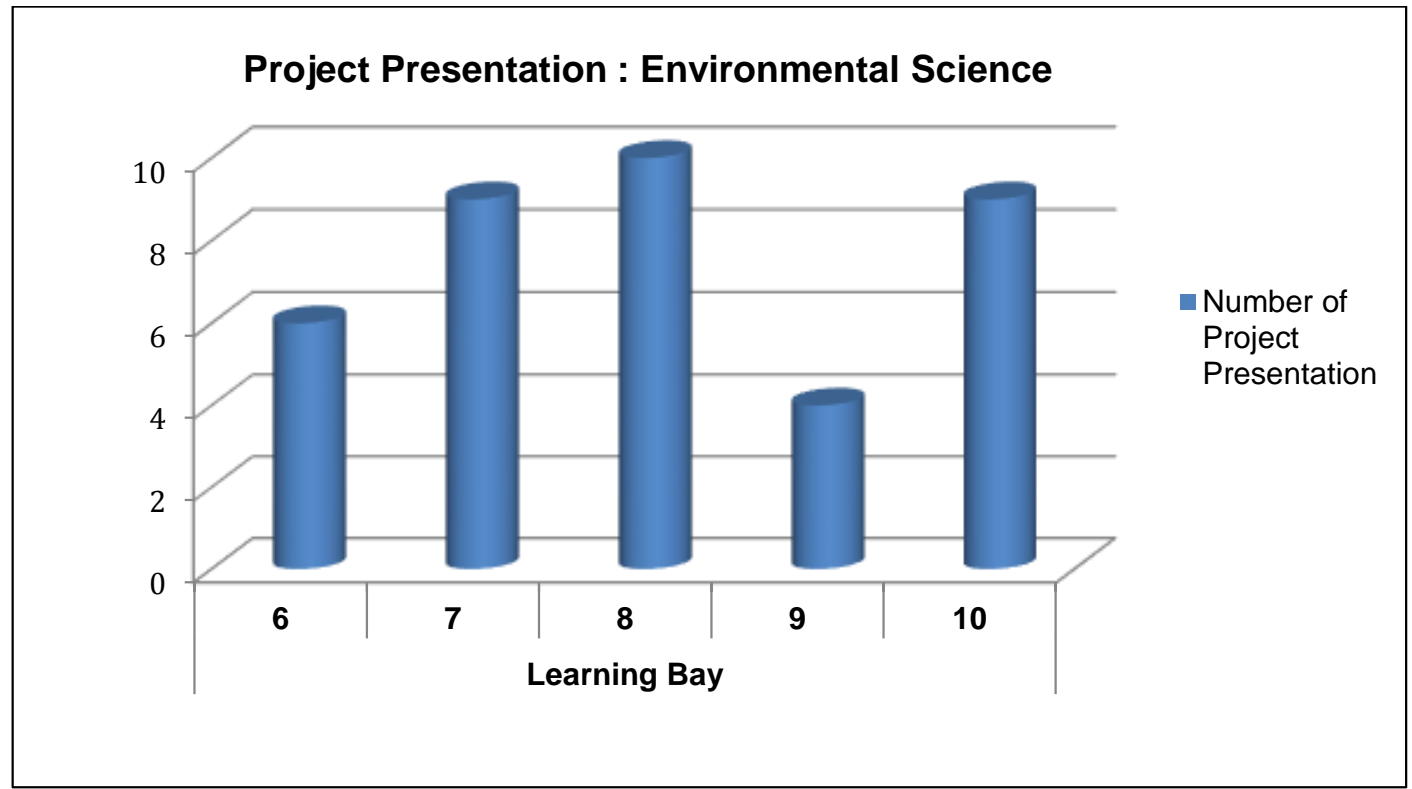

Use of ICT and Mode of Presentation

The project presentation should be online. The main advantage of the online presentation is that it has a lot of visual information. With the help of an online presentation, students can demonstrate all benefits of their projects in a convenient and attractive form, using 
multimedia files and narrations. The use of ICT and online project presentations will help to share their information in a matter of minutes. The online mode of project will be easier to upload in the library blogs and class blogs.

\section{Examples:}

- Create an online Project Presentation (www.prezi.com).

- Use the ICT and internet to communicate and share ideas.

\section{Success Criteria of Multiple Intelligence based Projects}

The main and important success results of the Project Based Learning Approaches are;

- The library is always engaged by students, resulting in the maximum utilization of library resources,

- Sharing online projects for rest of the school,

- Improvement in academic performances,

- Progress in the use of technology in the library,

- Enhances critical thinking skills,

- Improved the Observation skills,

- Boosted cooperative learning skills,

- Improved curriculum knowledge,

- Development in the presentation skills, etc.

\section{Awards and Certificates}

The Awards and Certificates are given according to the performance criteria of students. The awards and certificates are best motivated for various activities. The function should be conducted at the end of the Academic Year.

\section{Student Volunteers/ Community Service}

Good readers can be good leaders. Students' participation is very important in the daily activities of an academic library. We have to encourage student volunteers in various activities like selection, labelling, covering, and arranging the books in the library. The library volunteers are recommended to be leaders for the Project Based Learning Approach and performance evaluation of the same. Librarian also utilizes the library volunteers' help to upload the library website regularly.

\section{Conclusion}

I have mainly tried to show in this professional paper that, the possibilities to implement the 21st Century learning Skills in the school library with increase reading habits among students. The Libraries are useful in curriculum based researches, collaborative learning and growing, improving communication and presentation skills and motivating reading habit among the students.

On the basis of above mentioned plans and learning activities, the role and possibilities of school libraries as windows to the world of information. All the above mentioned activities are true and really successful in my last few years' professional experience.

This paper shows and discusses the last few years of successful professional experiences on encouraging Reading Activities and Project Based Learning Approach in school library. This is 
a true story and is still being conducted in the school library and outlines as to how the libraries are useful in curriculum based researches, collaborative learning and growing, improving communication and presentation skills along with motivating reading habit among the students. Looking forward to challenging and rewarding position in the library has with it opportunities for an individual who is aggressive and dedicated which is essential for achieving the $21 \mathrm{st}$ Century educational goals.

\section{References}

School Library Website: The Westminster School, Dubai, UAE www.librarytwsdxb.weebly.com

\section{Biographical note}

Mr. Raghunathan. M.O., Senior Librarian and Project based learning Coordinator, The Westminster School, Dubai, UAE has been working in UAE since 2007. He holds a Master's Degree in Library and Information Science. He is working as a Senior Librarian and Project Based learning Coordinator for the last three years. He has more than ten years' experience in the field of education and well experienced librarian in IGCSE and CBSE curriculum schools.

Mr. Raghunathan has over eight years of extensive gulf work experience in a multicultural environment, conducting various activities to encourage reading habits among the students, leading the library team and managing a well-stocked library with ICT section and conducting various activities on Literacy and Project Based Learning activities in the library. He has transformed the Library environment, from being a Reading centric place to an Activity and Research based Centre.

Mr. Raghunathan was nominated for the "Best Admin Award 2013-2014" from The Westminster School (A GEMS managed School), Dubai, UAE for his excellent contribution to the institute. He is a member of UAE School Librarian's network and GEMS Librarian's network. 